\title{
Os percursos de navegação durante a resolução do problema de Carbópolis: centralidade e extensibilidade.
}

\author{
Marcelo Leandro Eichler ${ }^{1}$ \\ Léa da Cruz Fagundes**
}

Resumo: Neste artigo, descrevemos o uso de arquivos de $\log$ na análise da utilização do software educativo Carbópolis. A análise desses arquivos foi combinada à análise microgenética buscando evidenciar os percursos de navegação e os mecanismos psicológicos manifestos pelos sujeitos durante a resolução do problema apresentado pelo software. Realizou-se a pesquisa com a colaboração de oito participantes, com idades entre 14 e 17 anos. A partir dos dados obtidos na pesquisa, propõem-se duas categorias para a análise dos percursos de navegação em hipertextos ou em simulações educacionais: centralidade e extensibilidade.

Palavras-chave: Hipertexto; Microgênese; Solução de problemas.

Abstract: [Navigation paths during a problem solving in Carbopolis software: centrality and extensibility]. This paper describes the application of log files to analyze the use of Carbopolis educative software. The log files analysis was combined with migrogenic analysis aiming at demonstrating navigation paths and psychological mechanisms expressed by the individuals when solving a problem presented by the software. This research counted with 8 participants aged between 14 and 17 years old. From the obtained data, two categories for the analysis of navigation paths in hypertexts or in educational simulations are proposed: centrality and extensibility.

Key words: Hypertext; Microgenetic analysis; Problem solving.

\footnotetext{
${ }^{1}$ Licenciado em Química e Doutor em Psicologia do Desenvolvimento pela UFRGS, é professor da UERGS e pesquisador da Área de Educação Química (AEQ) da UFRGS. Autor correspondente: exlerbr@yahoo.com.br.

" Pedagoga e Psicóloga e Doutora em Psicologia pela USP, é professora da UFRGS e coordenadora do Laboratório de Estudos Cognitivos (LEC) da UFRGS.
} 


\section{Introdução}

A produção de energia elétrica e seus os impactos ambientais e sociais tem sido o tema de um projeto de desenvolvimento de material didático computacional no âmbito da didática das ciências, articulado pela Área de Educação Química da UFRGS (Eichler, Gonçalves, Silva, Junges e Del Pino, 2003). O primeiro produto deste projeto foi o software Carbópolis (Eichler e Del Pino, 2000), cuja temática é o impacto ambiental provocado pela chuva ácida decorrente da queima de carvão mineral em usinas termoelétricas. Esse software recentemente foi premiado na edição 2005 do Programa de Apoio à Pesquisa em Educação à Distância.

Nos últimos anos, foram publicados artigos de análise sobre a utilização de Carbópolis em diferentes realidades de escola (Guterres, Eichler e Del Pino, 2003 e 2004) e sobre a elaboração conceitual de estudantes que fizeram uso do software (Eichler, Del Pino e Fagundes, 2004; Eichler e Fagundes, 2001 e 2004). Neste artigo, pretendemos retomar uma análise desenvolvida durante trabalho de pós-graduação (Eichler, 2000) que permanecia não publicada.

Entretanto, antes que se aborde essa análise, descrevemos um pouco o software. Carbópolis é um software educativo de distribuição livre ${ }^{2}$, desenvolvido em tecnologias JAVA e MySQL (Eichler, Xavier, Araújo, Forte e Del Pino, 2005), que utiliza uma estratégia de resolução de problemas para abordar um tema ambiental. O problema apresentado em Carbópolis consiste na diminuição da produção agropecuária em uma localidade próxima a uma usina termelétrica. Para resolvê-lo o estudante pode verificar os danos causados, a origem dos mesmos e propor uma solução que venha a diminuí-los ou eliminá-los.

O software foi modelado a partir de dados de uma pesquisa a respeito do potencial poluidor da usina termelétrica de Candiota, Rio Grande do Sul (Fiedler, Martins e Solari, 1990). Essa pesquisa indicou que as medidas de controle de emissões e as exigências legais eram inadequadas ou insuficientes para evitar a contaminação ambiental. A situação concreta pode ser assim descrita: na usina termelétrica de Candiota, a queima de carvão contendo taxas de enxofre maiores que o recomendável, entre 3,5 e 5\% (em Carbópolis essa taxa aumenta para 6\%), produziu grandes quantidades de dióxido de enxofre, um gás bastante reativo e que é considerado poluente atmosférico. O dióxido de enxofre foi dissipado na atmosfera através da ação dos ventos, em direção ao Uruguai (em Carbópolis, em direção a região agropastoril). A umidade do ar e a água da chuva reagiram com o gás poluente e ocorreu a precipitação de chuva ácida, que queimou os pastos e as lavouras de arroz (em Carbópolis, as lavouras são de soja) e, provavelmente, atacou o sistema respiratório e digestivo dos animais, enfraquecendo-os. Além do que foi exposto, que têm relação com o sistema físico-químico da análise ambiental, no software Carbópolis foram acrescidas algumas considerações sobre os ecossistemas, os aspectos econômicos e a legislação aplicável.

Com o objetivo de propiciar que o usuário proponha uma solução para o problema, o software contém: a) um mapa para auxiliar a situação geográfica do problema apresentado; b) personagens para descrever o problema; c) menu e ícones que possibilitam a coleta das amostras de ar e água da chuva sobre o mapa, análise das amostras e instalação de equipamentos antipoluentes; d) ferramenta de editor de textos para registrar conclusões parciais e o resultado das análises das amostras durante a utilização do software; e) um hipertexto com tópicos relacionados ao problema simulado; e f) dois questionários para orientar a conclusão das atividades propostas pelo software.

\footnotetext{
${ }^{2} \mathrm{O}$ software pode ser obtido em www.iq.ufrgs.br/aeq/carbop.htm
} 
A estrutura do hipertexto é poliierarquizada e reticular, tendo sido planejada através de diferentes eixos temáticos. A Figura 1 contém uma representação da estrutura desse hipertexto. Os assuntos desses eixos são: estratégias para a solução do problema (abreviatura: metocien; número do tópico no arquivo de log: 15), poluição atmosférica (polar; 440), técnicas e parâmetros para amostragem (amos1; 20) e análise (anal1; 50), legislação (legisla; 45), ecossistemas (ecossis; 280) e aspectos econômicos (aspeco; 110). Posteriormente, foram criados textos relacionados a tais eixos. Quando se julgou necessário ampliar o assunto de algum desses textos, novos tópicos foram produzidos. Finalmente, quando se considerou que a quantidade de informações do hipertexto era suficiente para o apoio à solução do problema proposto no software Carbópolis, os tópicos foram interligados. A estrutura final contém 56 tópicos e mais de 250 ligações ativas. Como se observa, esse desenvolvimento foi bastante subjetivo, sendo muito influenciado pelos parâmetros pedagógicos que inspiraram o projeto de produção desse software educativo.

Nesse sentido, estudos com arquivos de log têm buscado, por exemplo: a observação dos processos de navegação hipermídia (Barab, Bowdish e Lawless, 1997); o exame de estratégias que aprendizes empregam quando navegam através de materiais hipermídia, com diferentes formas de organização para neles adquirir conhecimento (Beasley e Waugh, 1997); e a avaliação da utilização e da eficiência de estudantes em ambientes controlados por multimídia (Lawless e Brown, 1997).

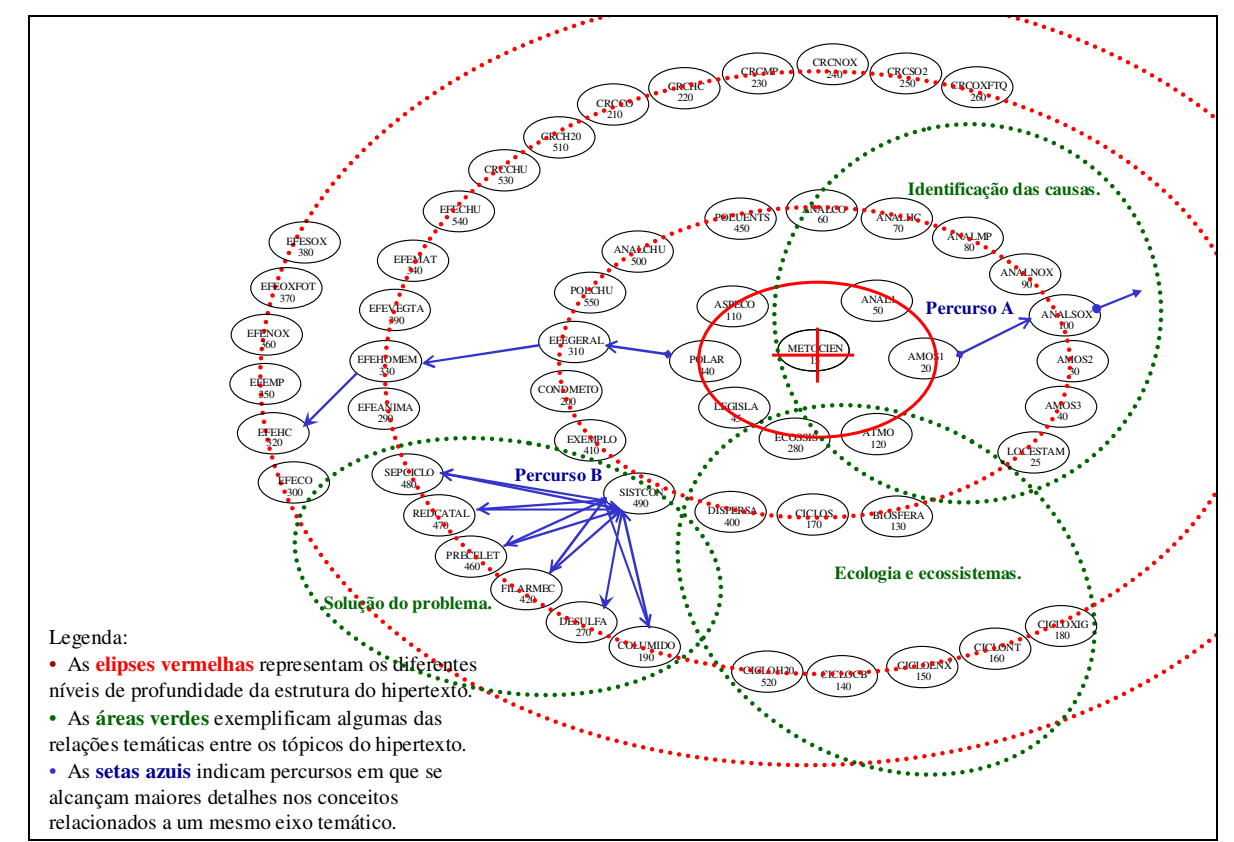

Figura 1 - Esquema de estrutura do hipertexto, que foi utilizado para auxiliar a interpretação dos arquivos de $\log$.

Em geral, os programas de computador utilizados nas pesquisas com o uso de arquivos de $\log$ possuem a estrutura de hipertexto hierarquizada (Barab, Bowdish e Lawless, 1997; Beasley e Waugh, 1997; Lawless e Brown, 1997). Embora não tenham sido encontrados estudos similares a esta pesquisa, entende-se que tais registros, também, podem ser úteis para indicar o processo de resolução de problemas desenvolvido em um contexto particular, com o apoio de um hipertexto com estrutura reticular. 


\section{Metodologia}

Nesta pesquisa, utilizou-se a análise microgenética para estudar o processo de elaboração cognitiva (Moro, 2000) durante a utilização do software Carbópolis. A análise microgenética foi desenvolvida sob tradição de pesquisa de inspiração piagetiana (Inhelder e Céllerier, 11996). A análise microgenética permite apreender o funcionamento do pensamento do sujeito psicológico individual e possibilita evidenciar os processos de resolução de problemas de que se utiliza durante a realização de uma tarefa. Nesse tipo de pesquisa, a variável estrutural é controlada, pois a população observada situa-se em uma mesma etapa de desenvolvimento cognitivo, o que permite evidenciar as diferenças e particularidades em cada sujeito. Análises com essa ênfase são chamadas de microgenéticas porque seguem um caminho temporal mais curto de um desenvolvimento macrogenético bem mais longo. Nesses estudos com o sujeito psicológico individual, o interesse é revelar a dinâmica das condutas do sujeito, suas avaliações, suas intenções e valores, as escolhas que faz dos meios e os controles que utiliza, enfim, as heurísticas próprias ao sujeito que podem levar a um mesmo resultado, através de caminhos diferentes.

Na microgênese, parte-se da hipótese de que o conhecimento inicial ativado pelo sujeito, que se encontra no início da resolução de um problema, ainda não está atualizado ou especificado. Esse conhecimento é sincrético, ou seja, é uma reunião artificial de idéias de origens disparatadas, uma vez que a visão de conjunto da totalidade ainda se encontra confusa. Pode-se entender essa reunião como a amálgama de duas componentes, uma de generalidade difusa relativamente à situação atual, e outra de particularismos justapostos em relação aos conhecimentos anteriores sobre os quais se apóia. Desse entender global e indistinto, surgem os objetos distintamente entendidos, transformando-se progressivamente em um saber ao mesmo tempo preciso e sintético. Portanto, a construção microgenética consiste numa dupla passagem do difuso ao preciso, e do esparso ao unitário.

É nesse sentido que entendemos que os estudos microgenéticos podem oferecer, se não uma explicação, no mínimo, uma descrição mais ampla dos diferentes padrões de navegação em hipertexto e de utilização de simulações educacionais.

Nesta pesquisa, o estudo microgenético foi realizado com a colaboração de oito participantes, com idades entre 14 e 17 anos, a partir de um delineamento de estudo de casos. Os participantes utilizaram o software em sessões de 45 minutos, sendo utilizadas tantas sessões quanto fossem necessárias para os participantes resolverem o problema proposto. Durante a solução da tarefa foram utilizados a observação sistemática e o método clínico. Conforme as características do estudo microgenético, foram limitadas as interferências do experimentador, que acompanhou todo o processo. Dessa forma, foram previstos três momentos de intervenção do experimentador para a entrevista clínica.

As seguintes questões serviram, em geral, como norte para as perguntas que foram efetivamente feitas: 1) quando os participantes conseguissem situar geograficamente o problema, o experimentador perguntaria algo sobre o porquê o problema estaria assim situado, como o participante chegara a essa conclusão, qual a explicação que ele poderia dar ao problema e como ele iria resolvê-lo; 2) quando os participantes identificassem uma possível causa ao problema, o experimentador perguntaria porquê o participante atribuíra essa possível causa, como fizera para chegar a tal conclusão, como poderia garantir que fosse essa a causa do problema, qual a explicação para essa possível causa e o quê poderia ser feito para resolver o problema; e 3) finalmente, quando os participantes resolvessem o problema, o experimentador perguntaria como o participante chegara a essa conclusão, como ele poderia explicá-la e se o problema que lhe fora apresentado existe, existiu ou pode existir na realidade. As 
entrevistas foram gravadas em fitas de áudio e posteriormente transcritas. Além disso, as atividades realizadas com o programa de computador foram gravadas por uma rotina de histórico, chamada de arquivos de $\log$.

A análise microgenética de cada caso, ou seja, de cada participante, foi feita com os seguintes dados: a descrição do histórico da utilização do software; os textos escritos pelos participantes durante a utilização do software (bloco de notas e relatórios); e a transcrição das fitas de áudio. A triangulação desses dados foi efetivada através da construção de protocolos. Os dois primeiros tipos de dados permitiram uma descrição do desenrolar das descobertas realizadas pelos participantes com relação ao problema ambiental. O terceiro se somou aos anteriores para descrever as condutas cognitivas dos participantes na solução da tarefa.

No entanto, as técnicas de análise dos arquivos de log usadas em diversas pesquisas (Barab, Bowdish e Lawless, 1997; Beasley e Waugh, 1997; Lawless e Brown, 1997) possuem natureza estatística, não sendo próprias para a interpretação dos dados que foi realizada nesta pesquisa. Dessa forma, foi necessário desenvolver um método para a análise qualitativa que se queria empreender aos arquivos de $l o g$.

$\mathrm{O}$ método que foi elaborado para interpretar qualitativamente os dados dos arquivos de log foi apoiado por um esquema radial, conforme se pode ver na Figura 1. Nesse esquema foram representadas algumas das características desse hipertexto, que constaram de cinco níveis. Os dois níveis mais internos contêm os tópicos relacionados aos eixos temáticos do hipertexto. Na disposição dos diferentes tópicos no esquema se procurou ladear os tópicos segundo as relações temáticas que entre eles existisse, bem como para os tópicos relacionados à identificação e à solução do problema proposto. Com o auxílio desse esquema foi possível descrever os percursos entre os tópicos seguidos durante a navegação. Além das navegações pelo hipertexto, nesse esquema é possível descrever a execução de procedimentos do software relacionados à análise ambiental, tais como as análises de poluentes e a instalação e desinstalação dos equipamentos antipoluentes.

Como já foi enfatizado, os arquivos de log permitiram acompanhar o encadeamento dos percursos de navegação no hipertexto e dos procedimentos realizados em direção à solução do problema. Uma vez que esses percursos estavam descritos nesse esquema, foi possível buscar uma interpretação apoiada, entre outras: pela centralidade das consultas em um determinado tópico ou em um certo assunto e pela extensibilidade manifestada na consulta de diversos tópicos em um mesmo eixo temático. Por exemplo, entende-se que um sujeito que manifesta certeza sobre a causa do problema em questão, em princípio, segue uma consulta centralizada sobre os tópicos relacionados a essa certeza. No entanto, apesar de manifestar tal certeza, o mesmo sujeito pode não saber como solucionar o problema, mesmo que saiba da necessidade da instalação de um determinado equipamento antipoluente, então seu percurso evidenciaria a extensibilidade na consulta dos tópicos, que indicaria que o sujeito buscou diversos equipamentos, sem ter uma hipótese formada sobre qual seria o mais indicado para solucionar o problema.

A seguir serão apresentados pequenos trechos dos protocolos e das análises que empreendemos, com o objetivo de ilustrar a utilização que fizemos do método microgenético com o apoio dos arquivos de log para descrever e interpretar os percursos de navegação dos usuários de Carbópolis durante a solução do problema proposto. 


\section{Resultados e discussão}

Conforme se pôde constatar pelas análises dos protocolos, a utilização do hipertexto propiciou a construção da hipótese sobre a causa do problema proposto ao estudante. Por exemplo, no início do programa, Carla (14 anos e 7 meses) se mostrava bastante confusa e afirmava nada saber sobre o problema, ou como resolvê-lo ou de que forma usar o software. Depois de vários tateios, começou a navegar pelo hipertexto, o que ocorreu durante 19 minutos e 45 segundos contínuos. No entanto, não foi possível registrar a concisão de sua hipótese nem por excertos no bloco de notas, por que ela não usava esse procedimento, nem nas entrevistas, pois ela, foi reticente quanto sua negativa às gravações, ou ela não falava ou o fazia muito baixo, não sendo possível interpretar suas declarações. Por outro lado, as observações registradas durante a sessão indicam que ela formulou uma hipótese relacionada ao dióxido de enxofre como fator causal.

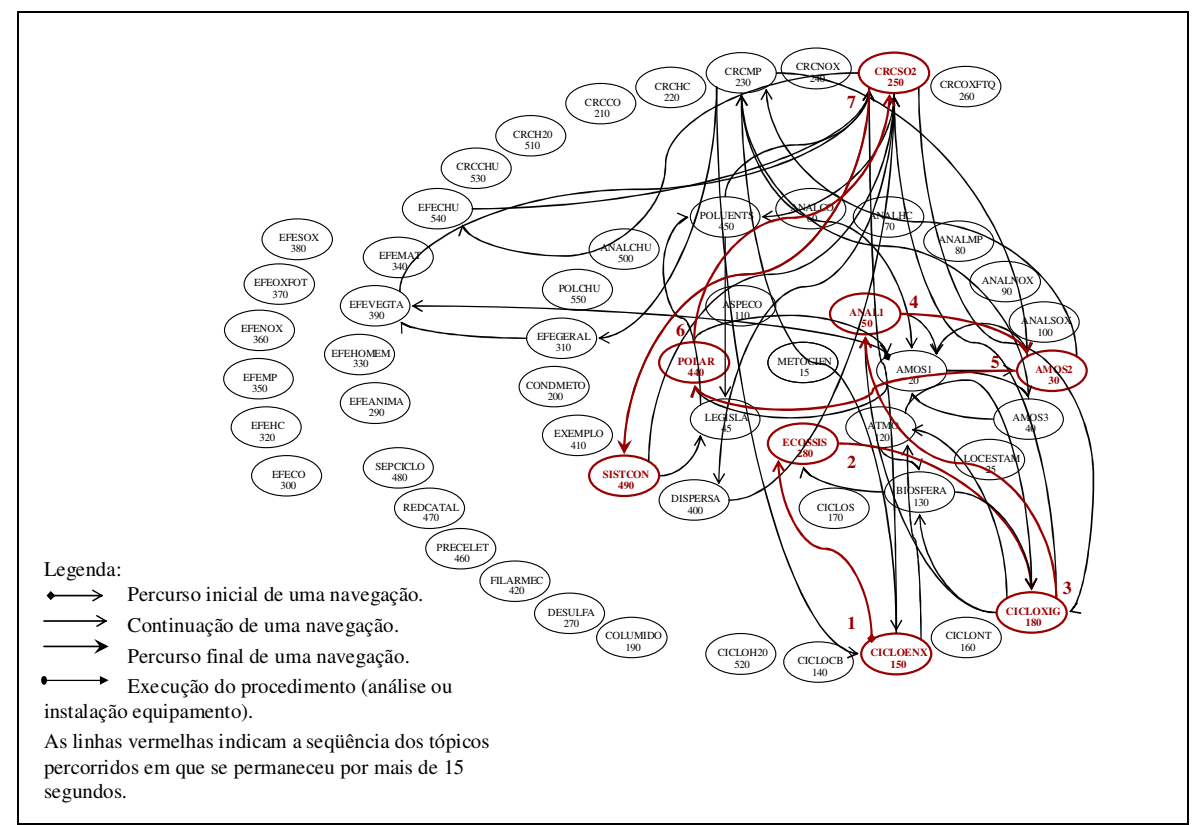

Figura 2 - Percursos de navegação de Carla.

A navegação desenvolvida por Carla mostrou que a passagem pelos tópicos não pode ser o único parâmetro envolvido na análise dos arquivos de $\log$, conforme pode-se depreender dos percursos de sua navegação, representada na Figura 2. Carla manifestou uma utilização do hipertexto muito frenética, trocando de tópicos várias vezes e de forma muito rápida, em muitos deles, permanecendo por muito pouco. Nesse sentido, a representação das ligações entre os tópicos muito pouco teriam a dizer sobre a construção de sua hipótese. Dessa forma, utilizou-se outro critério, que levava em conta o tempo de permanência em cada tópico. Arbitrariamente se escolheu um tempo mínimo de 15 segundos de permanência em cada tópico e se decidiu fazer um outro registro da evolução da navegação. Esse critério pareceu ser bastante descritivo para mostrar a consecução do seu navegar e, assim, considerou-se possível indicar a formação de sua hipótese: ela começou a prestar atenção no tópico relacionado ao ciclo do enxofre (1min, 01s), depois parou junto ao de ecossistemas (51s), passando pelo ciclo do oxigênio (20s), principais parâmetros a determinar (17s), equipamentos para determinação de poluentes na atmosfera (36s), poluição do ar (55s), dióxido de enxofre $(59 \mathrm{~s})$ e, finalmente, sistemas de controle de poluição do ar (37s). Também, é interessante ressaltar que metade desses tópicos possui figuras, inclusive os três primeiros. Talvez isso tenha chamado sua atenção e ela terminou por permanecer mais tempo nesses tópicos. 
A triangulação propiciada com o uso dos arquivos de $\log$, a representação dos percursos de navegação no software e os critérios de extensibilidade e de centralidade também foram úteis para interpretar as formas de confirmação das hipóteses levantadas pelos sujeitos.

Os parâmetros escolhidos para a análise - material particulado (Analmp; 80), hidrocarbonetos (analhc; 70), monóxido de carbono (analco; 60), óxidos de nitrogênio (analnox; 90), dióxido de enxofre (analsox; 100), de $\mathrm{pH}$ da água da chuva (analchu; 500) - podem indicar os controles cognitivos utilizados pelo sujeito: se dirigido por uma hipótese ou se pela elaboração de fatos contingentes. Conforme se vem propondo, nas representações gráficas dos percursos de navegação são utilizados critérios de centralidade e extensibilidade para evidenciar isso.

Na fase de identificação do problema, Paulo (14 anos) já possuía uma hipótese que fora confirmada por suas análises. Conforme se pode notar na Figura 3, as ações de Paulo voltadas à identificação do problema manifestaram uma centralidade contínua na busca do parâmetro de análise para evidenciar a causa do problema (percursos 1, 6, 9, 10, 12 e 13; as setas indicam a execução do procedimento de análise).

No entanto, Paulo não manifestou essa mesma centralidade na busca da solução do problema, pelo contrário, o que ocorreu foi uma recorrência extensa aos tópicos relacionados aos sistemas de controle de poluição do ar. Paulo manifestou saber que deveria instalar um, em suas palavras, "controlador de poluição", porém não sabia qual e não evidenciou uma procura dirigida por uma hipótese muito bem definida. Dessa forma, seu procedimento de consulta ao hipertexto e a navegação entre as funções do programa muda substancialmente. Paulo pára de se orientar por uma hipótese bem formada e objetiva em relação ao problema em questão e começa a usar um procedimento de tentativa e erro. Nesse caso, é possível confirmar que a extensibilidade manifestada na consulta aos tópicos (percursos 7, 8, 11 e 13; as setas indicam a execução dos procedimentos de instalação ou de desinstalação de equipamento antipoluente) pode servir de evidência a procedimentos dessa natureza, conforme Figura 4.

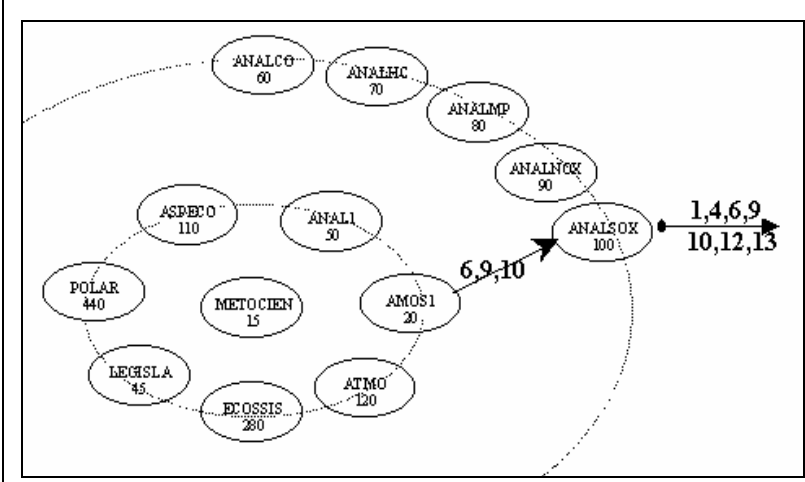

Figura 3 - Centralidade manifestada na análise de poluentes atmosféricos, por Paulo.

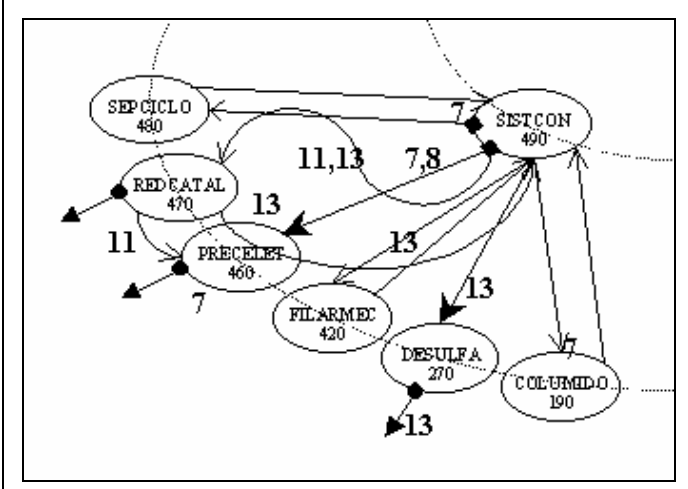

\begin{tabular}{lcc} 
Figura 4 & - & \multicolumn{2}{c}{ Extensibilidade } \\
manifestada & na instalação & de \\
equipamentos & antipoluentes, por \\
Paulo. & & \\
\end{tabular}

Nesse particular, é interessante notar que seu procedimento de leitura contribuiu bastante para essa manifestação de solução por tentativa e erro. Na navegação inicial entre os tópicos relacionados aos sistemas de controle de poluição permaneceu por tempos muito pequenos: 13 segundos (Separador Ciclópico; 480), 24 segundos (Coletor Úmido; 190) e 32 segundos (Precipitador Eletrostático; 460). Pode-se dizer que Paulo não mostrou consistência nem na escolha que fizera, nem na certeza de seu resultado, 
parecendo tatear a solução do problema, conforme extrato de seu arquivo de $\log$, vide Tabela 1.

Tabela 1 - Excerto do arquivo de log do Paulo.

Ação

Hora

Tópico da Biblioteca 490

Tópico da Biblioteca 480

Tópico da Biblioteca 490

Tópico da Biblioteca 190

Tópico da Biblioteca 230

Tópico da Biblioteca 190

Tópico da Biblioteca 490

Tópico da Biblioteca 460

Colocou Precipitador Eletrostático

Entrevista RP da Usina

Entrevista Guarda Florestal

Tópico da Biblioteca 490

Tópico da Biblioteca 460

Colocou Precipitador Eletrostático

Tópico da Biblioteca 100

Analisou SO2

Tópico da Biblioteca 100

Analisou SO2
27/09/99 14:48:06

27/09/99 14:49:41

27/09/99 14:50:04

27/09/99 14:50:10

27/09/99 14:50:34

27/09/99 14:50:50

27/09/99 14:50:52

27/09/99 14:50:58

27/09/99 14:51:30

27/09/99 14:51:42

27/09/99 14:52:15

27/09/99 14:52:31

27/09/99 14:52:47

27/09/99 14:52:58

27/09/99 14:53:17

27/09/99 14:53:23

27/09/99 14:54:17

27/09/99 14:54:20

Um outro caso nos permite ponderar algumas coisas em relação aos usos dos critérios de centralidade e extensibilidade e a triangulação das diferentes fontes de dados usadas nesta pesquisa.

Na identificação do problema, pôde-se evidenciar que Piter (15 anos e 3 meses) desenvolveu uma ação por tentativa e erro, manifestando a extensibilidade na consulta aos tópicos relacionados à análise dos poluentes atmosféricos. Na Figura 5, isso pode ser evidenciado pela consulta dos tópicos relacionados à identificação do problema, ou à análise de amostras, conforme os percursos de 1 a 7. Também, é importante verificar que Piter procede com a análise de $\mathrm{pH}$ da água da chuva e inclui esse parâmetro no nexo causal do problema, desenvolvendo seu esboço explicativo: "(Piter): Fazendo as análises do amostrador, eu vi que tem vários outros componentes que também tão a mais e que prejudicam o ar, como o dióxido de enxofre, o monóxido de carbono, óxidos de nitrogênio e ozônio, e também a água da chuva, né, que é uma água ácida. (Entrevistador): Porque a água tá ácida? (Piter): Por causa do, porque tem, tá dando, tem vários componentes no ar, na água também, sabe? Tem outros ácidos que provocam, acidez da chuva, né".

Porém, se essa foi a conduta inicial de Piter, isso deixou de ocorrer quando procurou solucionar o problema, através da instalação de equipamentos antipoluente. As análises dos poluentes atmosféricos, agora relacionadas à avaliação da eficiência dos diferentes equipamentos antipoluentes instalados na usina, evidenciaram a centralidade das consultas aos tópicos (percursos 15, 16, 19, 22, 24, 26 e 28 na Figura 5). Nesse sentido, Piter progrediu na seqüência causal. No início dessa fase, ainda desenvolvia o procedimento de análise do $\mathrm{pH}$ da água da chuva. Porém, no momento que construiu a certeza de que a diminuição desse índice era devido às concentrações dos poluentes atmosféricos, deixou de analisar o $\mathrm{pH}$ da água da chuva e procurou pelo poluente que 
estaria ocasionando tal abaixamento. Posteriormente, quando toma a certeza da causa pelo dióxido de enxofre, apenas procede com essas análises.

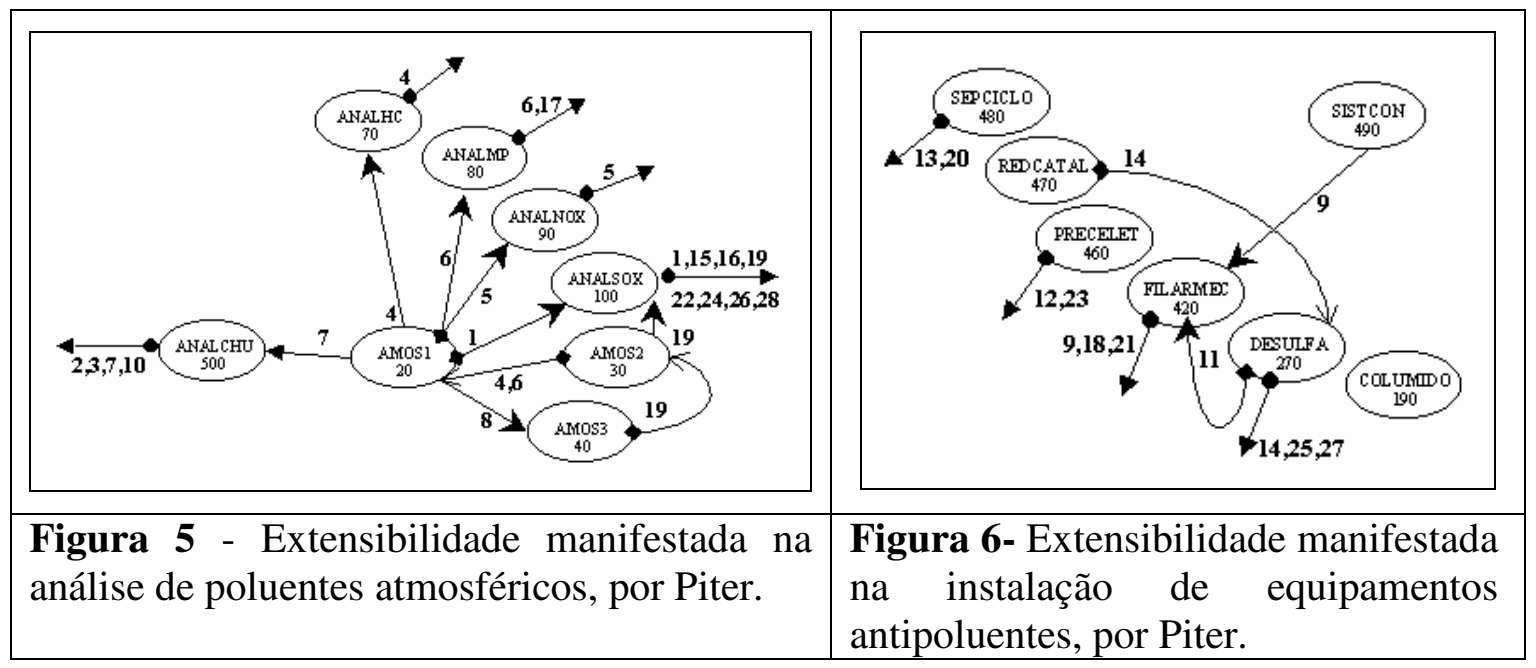

Embora Piter tenha manifestado um procedimento de análise que tenha se valido de praticamente todos os padrões de análise isso não evidencia, necessariamente, que ele não tenha construído uma hipótese acerca da identificação do problema. Ao contrário, ele parece desenvolver esse expressivo número de análises para confirmar a relação que ele já esboçara entre o alto índice de dióxido de enxofre e a diminuição no valor do $\mathrm{pH}$. Isso, por exemplo, pode ser inferido desde a solução que ele, nesse momento, indicou para resolver o problema: "(Entrevistador): E como é que tu achas que pode resolver o problema? (Piter): Ah, botando alguma coisa no ar, né, que elimine o enxofre".

Nesse sentido, a extensibilidade da consulta dos tópicos indica, de forma diferente do que ocorrera no caso Paulo, um procedimento metódico para confirmação da hipótese, ou seja, um mecanismo para submeter à prova ao exame sistemático, para se chegar a uma certeza mais cabal, sem dúvidas. Possivelmente, o procedimento de testagem sistemática de suas certezas levou Piter a uma demora na identificação e solução do problema que nem mesmo ele esperava.

É interessante ressaltar as dificuldades de entendimento de conceitos químicos relacionados à linguagem, evidenciadas, por exemplo, na etapa de solução do problema. $\mathrm{O}$ único equipamento eficiente para suprimir a causa da poluição se chama dessulfurizador, isso porque ele procede a dessulfuração dos combustíveis fósseis, ou seja, retira o enxofre presente nesses combustíveis. Porém, qual a relação entre o termo enxofre e o afixo 'sulfur'? Isso pode parecer óbvio para um químico, mas não é de conhecimento geral. Nesse sentido, essa associação de termos pode indicar a relativa dificuldade de certos sujeitos em estabelecer o método de controle de poluição do ar mais eficiente para o problema proposto, mesmo que a essa dificuldade se deva acrescentar a falta de atenção na leitura dos tópicos relacionados aos equipamentos, conforme indica o extrato do arquivo de $\log$ apresentado anteriormente. As figuras $4 \mathrm{e}$ 6 , evidenciam, por exemplo, o procedimento de solução por tateamento, por tentativa-eerro, como se pode verificar pela extensibilidade manifestada na instalação dos equipamentos antipoluentes. 
Conclusões

A metodologia escolhida para esta pesquisa foi a microgênese, que é um modelo de investigação que permite inferir sobre a consecução dos procedimentos e das compreensões que os sujeitos manifestam.

Durante a pesquisa se utilizaram três formas para obter os dados que, posteriormente, foram elaborados em protocolos e, então, interpretados. Os métodos foram: a observação sistemática, a entrevista clínica com registro em áudio e a gravação em arquivos de log das interações dos sujeitos com a ferramenta computacional que lhes serviu de tarefa.

Por outro lado, também, foi enfatizada a necessidade de criar um método para análise qualitativa dos arquivos de $\log$. Nessa ocasião, duas proposições foram enunciadas: 1) entende-se que tais registros, também, podem ser úteis para indicar o processo de resolução de problemas desenvolvido em um contexto particular, com o apoio de um hipertexto com estrutura reticular; e 2) entende-se que estudos microgenéticos podem oferecer, se não uma explicação, no mínimo, uma descrição mais ampla dos diferentes padrões de navegação em hipertexto e de utilização de simulações. Além disso, duas categorias de análise foram desenvolvidas: centralidade, (relacionada à unidirecionalidade na consulta de tópicos) e extensibilidade (relacionada à múltipla consulta de tópicos em um mesmo eixo de tópicos).

Através da análise dos protocolos, continuamente, observou-se dois comportamentos distintos. Em um deles, pode-se dizer, o sujeito constrói uma hipótese acerca do problema e, a partir dessa hipótese, ele utiliza estratégias e procedimentos frente ao problema em questão. No outro, o sujeito interpreta as características apresentadas pelo meio sobre o qual ele tenta resolver o problema e constrói novos sistemas de procedimentos. Diversos estudos, também, têm evidenciado esses dois tipos de controle do sistema cognitivo. Tais controles têm sido revelados em diferentes contextos e podem ser denominados por, respectivamente, descendente e ascendente (Mosca, Silveira e Burigo, 1993), top-down e botton-up (Beasley e Waugh, 1997), inferências para frente (da predição à conseqüência) e inferências para trás (das conseqüências à predição) (Bindra, Clarke e Shultz, 1980), ou baseados nas idéias e baseados na evidência (Park e Pak, 1997).

No final desta pesquisa, em que se pese o pequeno conjunto de dados estudado e o baixo número de sujeitos participantes da pesquisa, parece que os postulados defendidos continuam válidos. Conforme se pôde observar nas seções anteriores, tanto os arquivos de log quanto as categorias elaboradas foram úteis para a interpretação dos dados. Nesse sentido, verifica-se a necessidade da continuidade dessas pesquisas para que se corrobore a utilização de tais método e categorias na interpretação de condutas cognitivas.

Agradecimentos:

Gostaríamos de agradecer: ao CNPq pelas bolsas de pesquisa concedidas aos autores desta pesquisa; ao coordenador da Área de Educação Química - UFRGS, Prof. Dr. José Cláudio Del Pino, pelo continuo apoio às discussões interdisciplinares; e ao Colégio de Aplicação da UFRGS pela estrutura que nos foi cedida para desenvolver esta pesquisa.

Referências bibliográficas:

BARAB, S.A.; BAWDISH, B.R. \& LAWLESS, K.A. Hypermedia navigation: profiles of hypermedia users. Educational Technology Research and Development, 45 (3), 23-41, 1997. 
BEASLEY, R.E. \& WAUGH, M.L. Predominant initial and review patterns of navigation in a fully constrained hypermedia hierarchy: an empirical study. Journal of Educational Multimedia and Hypermedia, 6 (2), 155-172, 1997.

BINDRA, D.; CLARKE, K.A. \& SHULTZ, T.R. Understanding predictive relations of necessity and sufficiency in formally equivalent "causal" and "logical" problems. Journal of Experimental Psychology: General, 109 (4), 422-443, 1980.

EICHLER, M.L. Um estudo sobre a microgênese da explicação de um problema ambiental. Dissertação de Mestrado em Psicologia do Desenvolvimento, Universidade Federal do Rio Grande do Sul, Porto Alegre, 2000.

EICHLER, M.L. \& DEL PINO, J.C. Carbópolis: um software para educação química. Química Nova na Escola, 11, 10-12, 2000..

EICHLER, M.L.; DEL PINO, J.C.; FAGUNDES, L.C. Development of cognitive conducts during a computer simulated environmental analysis. Chemistry Education Research and Practice, 5. (2), 157-174, 2004.

EICHLER, M.L. \& FAGUNDES, L.C. A microgênese da explicação de um problema ambiental: os casos Paulo e Piter. Psicologia: Reflexão e Crítica, 14 (3), 505-520, 2001.

EICHLER, M.L. \& FAGUNDES, L.C. Conductas cognitivas relacionadas con el análisis de problemas ambientales. Enseñanza de las Ciencias, 22 (2), 287-298, 2004.

EICHLER, M.L.; GONÇALVES, M.R.; SILVA, F.O.M.; JUNGES, F. \& DEL PINO, J.C. Uma proposta para o desenho interdisciplinar de ambientes virtuais de aprendizagem de ciências. Renote: Revista Novas Tecnologias na Educação, 1 (2), 2003.

EICHLER, M.L.; XAVIER, P.R.; ARAÚJO, R.C.; FORTE, R.C. \& DEL PINO, J.C. Carbopolis: A java technology-based free software for environmental education. Journal of Computers in Mathematics and Science Teaching, 24 (1), 43-72, 2005.

FIEDLES, H.; MARTINS, A.F. \& SOLARI, J.A. Meio ambiente e complexos carboeléticos: o caso Candiota. Ciência Hoje, 12 (68), 38-45, 1990.

GUTERRES, J.O.; EICHLER, M.L.; DEL PINO, J.C. A usabilidade de Carbópolis, um software livre para a educação ambiental. Tecnologia Educacional, 166, 69-82, 2004.

GUTERRES, J.O.; EICHLER, M.L.; DEL PINO, J.C. Compreensões de professores sobre o software educativo Carbópolis e sua utilização em diferentes realidades de escola. Revista Brasileira de Informática na Educação, 11 (2), 86-99, 2003.

INHELDER, B. \& CELLÉRIER, G. O desenrolar das descobertas da criança: um estudo sobre as microgêneses cognitivas. Porto Alegre: Artes Médicas, 1996.

LAWLESS, K.A. \& BROWN, S.W. Multimedia learning environments: issues of learner control and navigation. Instructional Science, 25, 117-131, 1997.

MORO, M.L.F. A epistemologia genética e a interação social de crianças. Psicologia: Reflexão e Crítica, 13 (2), 295-310, 2000.

MOSCA, P.R.F.; SILVEIRA, J.F.P \& BURIGO, E. Processos cognitivos na resolução de problemas no campo da matemática: o caso da interação com programassemente. Psicologia: Reflexão e Crítica, 6 (1/2), 57-68, 1993.

PARK, J. \& PAK, S. Student's responses to experimental evidence based on perceptions of causality and availability of evidence. Journal of research in science teaching, 34 (1), 57-67, 1997. 